\title{
PENERAPAN METODE SIMPLE ADDITIVE WEIGHTING (SAW) PADA SISTEM PENDUKUNG KEPUTUSAN PENENTUAN PENERIMAAN DOSEN BARU
}

\author{
Agustina Heryati $^{1 *}$, A. Taqwa Martadinata ${ }^{2}$ Rezki Syahputra $^{3}$ \\ Program Studi Sistem Informasi, Universitas Indo Global Mandiri, Palembang ${ }^{1}$ \\ Program Studi Sistem Informasi, STMIK MBC Palembang, Palembang ${ }^{2}$ \\ Program Studi Teknik Informatika, Universitas Bina Darma, Palembang ${ }^{3}$ \\ e-mail: agustina.heryati@uigm.ac.id ${ }^{1}$,taqwa_martadinata@ stmikmbcpalembang.ac.id ${ }^{2}$, \\ rezkisyaputraharahap@gmail.com ${ }^{3}$
}

\begin{abstract}
Abstrak
Penentuan penerimaan dosen baru merupakan kegiatan yang selalu dilakukan setiap perbandingan antara dosen dengan mahasiswa belum terpenuhi. Di Universitas Indo Global Mandiri (Universitas IGM) membutuhkan waktu yang lama dalam menganalisa dan melakukan perangkingan untuk menentukan penerimaan dosen baru. Penerimaan dosen baru bertujuan agar mendapatkan dosen baru yang berkualitas dan sesuai dengan kriteria yang di butuhkan sehingga dalam pengambilan keputusan lebih cepat dan tepat. Perhitungan penerimaan dosen baru ini menggunakan metode Simple Additive Weighting (SAW). Metode ini melakukan pencarian penjumlahan terbobot dari kinerja yang terdapat perengkingan pada alternatif di semua atributnya. Kategori yang di pakai untuk perhitungan ini terdapat 3 (tiga) kategori yakni kategori kualifikasi pendidikan, tes psikotes, dan tes wawancara. Hasil penelitian ini dilakukan dengan menilai berdasarkan bobot menggunakan metode SAW, maka didapat 4 (empat) pelamar dengan nilai tertinggi yakni pelamar $1=52,5$; pelamar $2=50$, pelamar $3=32,5$ dan pelamar $4=57,5$. di lihat dari hasil pengolahan maka pelamar 4 memiliki nilai tertinggi yakni 57,5 menyatakan bahwa pelamar 4 di rekomendasikan menjadi dosen baru di Universitas IGM. Hasil dari penilaian penentuan penerimaan dosen baru dilihat dari perangkingan tertinggi dengan nilai rangking terbesar yakni pelamar ke 4 .
\end{abstract}

Kata Kunci : SPK; Metode Simple Additive Weighting; Penerimaan Dosen Baru

\begin{abstract}
Determining the admission of new lecturers is an activity that is always carried out every comparison between lecturers and students has not been fulfilled. At Indo Global Mandiri University (IGM University) it took a long time to analyze and rank to determine the admission of new lecturers. Admission of new lecturers is aimed at getting new lecturers who are qualified and in accordance with the required criteria so that decision making is faster and more precise. The calculation of new lecturer admissions uses the Simple Additive Weighting (SAW) method. This method performs a weighted sum search of the performance that is rated for the alternatives across all its attributes. The categories used for this calculation are 3 (three) categories, namely the category of educational qualifications, psychological tests, and interview tests. The results of this study were carried out by assessing based on weight using the SAW method, so there were 4 (four) applicants with the highest score, namely applicant $1=52.5$; applicant $2=50$, applicant $3=32.5$ and applicant $4=57.5$. In view of the results of the processing, applicant 4 has the highest score, namely 57.5, stating that applicant 4 is recommended to become a new lecturer at IGM University. The results of the assessment for determining the acceptance of new lecturers are seen from the highest ranking with the largest ranking value, namely applicant number 4.
\end{abstract}

Keywords : SPK Simple Additive Weighting Method; Acceptance of new lecturers 


\section{PENDAHULUAN}

Universitas menyediakan sumber daya manusia yakni dosen yang memiliki kompetensi dan keahlian yang di inginkan oleh pasar. Dosen harus memiliki penguasaan di bidangnya agar dapat menjadi dosen yang berkemampuan tinggi. Dosen berpartisipasi meningkatkan mutu pendidikan yang kelaknya mampu mencerdaskan kehidupan bangsa dan Negara melalui transformasi dan penyebaran ilmu pengetahuan melalui pengajaran, penelitian dan pengabdian kepada masyarakat [1]. Universitas menyeleksi dosen yang berkualitas dan propesional di mulai dari penerimaan dosen baru. Dosen haru memiliki kompetensi serta disiplin yang baik [2]. Dalam penerimaan dosen baru harus memiliki kualifikasi dan kriteria yang telah di tetapkan oleh pihak universitas diantaranya kualifikasi pendidikan dapat di lihat melalui ijazah magister atau S2 atau doktoran (S3) dan keahlian akademik serta kemampuan psikotesnya. Dosen harus mampu menyalurkan ilmunya pada masyarakat dan membuat lingkungan sekitar dalam proses belajar mengajar menjadi kondusif. Untuk itu di butuhkan kemampuan seorang dosen mengelola suasana kelas [3], juga di butuhkannya sebuah strategis promosi tepat juga dalam penerimaan mahasiswa baru sehingga menghasilkan universitas yang bermutu dan berkualitas [4].

Sebelumnya sudah pernah dilakukan penelitian mengenai Sistem Pendukung Keputusan (SPK) dengan metode SAW seperti penelitian yang dilakukan oleh Diini Salma Lutfi dalam sistem pendukung keputusan penerimaan dosen baru dengan metode simple additive weighting (SAW) [5]. Penelitian terkait juga pernah dilakukan oleh Nurtriana Hidayati yang berjudul analisis penerimaan dosen baru dengan menggunakan SAW (Simple Additive Weighting) [3]. Sedangkan Penelitian juga di kelola untuk sistem pendukung keputusan penerimaan pegawai baru menggunakan metode simple additive weighting (SAW) [6].

Berdasarkan penelitian sebelumnya dalam penerimaan dosen baru dengan menggunakan metode SAW menjelaskan Penilaian yang diambil adalah nilai tes microteaching dan nilai tes wawancara serta tes kemampuan bahasa inggris. Sedangkan Pada Penelitian di Universitas IGM proses seleksi penerimaan dosen baru telah di laksanakan calon dosen melakukan tes kualifikasi pendidikan (lineritas), tes psikotes, tes wawancara serta masih banyak kriteria lain yang sangat menentukan di jadikan ketentuan dalam penerimaan dosen baru. Dengan penentuan kriteria dan pengolahan penerimaan dosen baru tersebut membuat Universitas membutuhkan waktu lama dalam pengambilan keputusan, dikarenakan selain ketiga tes utama tadi (tes kualifikasi pendidikan, tes psikotes, tes wawancara) lebih diutamakan unsur 3P (Penganajaran, Pendidikan dan Pengabdian). Untuk itu di butuhkan sebuah analisis dan perangkingan dalam menentukan keputusan yang akan diambil oleh pihak universitas agar lebih cepat dan tepat [7] dalam menentukan dosen baru yang berkualitas.

Proses pengambilan keputusan calon dosen lebih tepat dibutuhkan metode dalam menghitung pengambilan keputusan seleksi yang baik dan mampu memberikan nilai yang akurat, salah satunya menggunakan metode SAW. SAW merupakan suatu metode yang mempunyai keahlian dalam melaksanakan perhitungan dalam mencari penjumlahan bobot melalui rating kinerja untuk masing-masing alternatif atribut, sehingga menghasilkan analisa dari sebuah keputusan penerimaan dosen baru yang baik dan tepat juga menginginkan proses yang cepat dalam pengambilan keputusan 
penerimaan dosen baru di Universitas IGM [8], [9].

Dengan adanya analisis dan perangkingan ini dapat di jadikan acuan dalam penentuan dosen baru dan dapat membantu Universitas IGM dalam menentukan keputusan yang tepat untuk merengkrut dosen dengan kualitas terbaik dan pilihan agar melahirkan generasi yang bermutu serta siap bersaing di masyarakat.

Tujuan Penelitian ini untuk mengetahui analisa penentuan penentuan penerimaan dosen barudi Universitas IGM dalam penerapan metode SAW. Dan untuk mengetahui pengambilan keputusan yang cepat dan tepat penerimaan dosen baru di Univeritas IGM.

\section{TINJAUAN PUSTAKA}

Rekrutmen adalah suatu usaha dalam pengisian pekerjaan yang di butuhkan pada lingkungan suatu organisasi untuk menempati suatu jabatan tertentu dalam fungsi pekerjaan [10]. Rekrumen dosen yang dilakukan oleh Universitas di sesuaikan dengan kualifikasi yang menjadi persyaratan dari Universitas tersebut. Penerimaan akan dosen baru berdasarkan penentuan kebutuhan jurusan yang menginginkan dan disesuaikan berdasarkan kemampuan yang diinginkan dengan mengutamakan kualifikasi yang telah di terapkan sebelumnya. [11], [12]. Sistem Penunjang Keputusan (SPK) atau Decision Support System (DSS) merupakan sistem yang dapat memecahkan masalah tertentu baik terstruktur maupun tidak terstruktur secara efektif dan efesien. SPK di rancang yang dapat diolah dengan mudah yang hanya mempunyai keahlian mengoperasikan komputer [13] .

SPK dapat membantu pihak Universitas dalam menentukan keputusan dengan melalui proses penilaian yang telah di tentukan sehingga dengan mudah menganalisis dan merangkingkan dalam penentuan penerimaan dosen baru pada Universitas IGM. [14].

SAW sering juga disebut dengan istilah metode penjumlahan terbobot. Konsep dasar SAW adalah menentukan penjumlahan memiliki bobot dari kinerja alternatif pada seluruh atribut. Metode SAW melakukan proses normalisasi matriks keputusan $(\mathrm{X})$ ke suatu skala yang kemudian membandingkan dengan seluruh rating alternatif yang ada.

Metode SAW banyak diolah untuk mengambil keputusan yang mempunyai banyak atribut. Metode SAW mengenal adanya 2 (dua) atribut yaitu kriteria keuntungan (benefit) dan kriteria biaya (cost).

Langkah Penyelesaian SAW Langkah Penyelesaian SAW :

1. MentukanAlternatif (Ai).

2. Menentukan kriteria yang akan dijadikan acuan dalam pengambilan keputusan, yaitu Memberikan nilai rating kecocokan setiap alternatif pada setiap kriteria.

3. Menentukan bobot preferensi atau tingkat kepentingan(W) setiap kriteria.

4. $\mathrm{W}=(\mathrm{W} 1, \mathrm{~W} 2, \ldots \ldots . \mathrm{Wj}) \ldots \ldots .1$

5. Membuat tabel rating kecocokan dari setiap alternatif pada setiap kriteria.

6. Membuat matrik keputusan $\mathrm{X}$ yang dibentuk daritabel rating kecocokan dari setiap alternatif padasetiap kriteria. Nilaixsetiap alternatif (Ai) padasetiap kriteria $(\mathrm{Cj})$ yang sudah ditentukan,dimana, $\quad \mathrm{i}=1,2, \ldots \mathrm{m} \quad$ dan $\mathrm{j}=1,2, \ldots$.

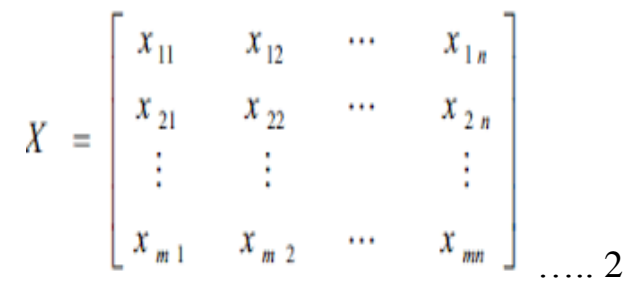


7. Melakukan normalisasi matrik keputusan dengan cara menghitung nilai rating kinerja ternomalisasi (rij) dari alternatif Ai pada kriteria $\mathrm{Cj}$.

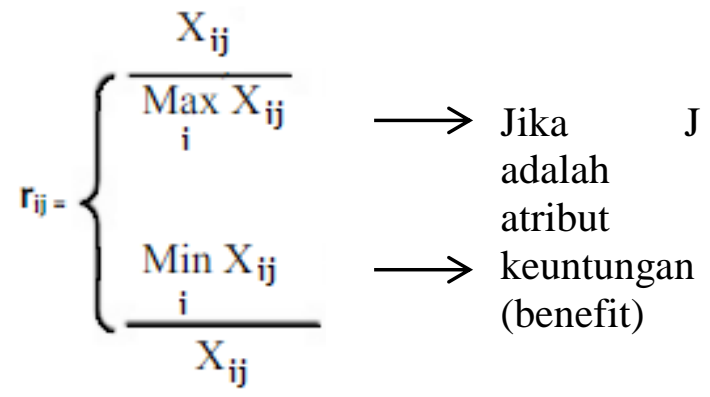

Keterangan :

$\mathrm{Ri} \quad$ :Nilai rating kinerja ternormalisasi

Xij :Nilai atribut yang dimiliki dari setiap kriteria

Maxi Xij :Nilai terbesar dari setiap kriteria

Mini Xij :Nilai terkecil dari setiap kriteria

Benefit :Jika nilai terbesar adalah terbaik

Cost :Jika nilai terkecil adalah terbaik

\section{METODOLOGI PENELITIAN}

\subsection{Rancangan Penelitian}

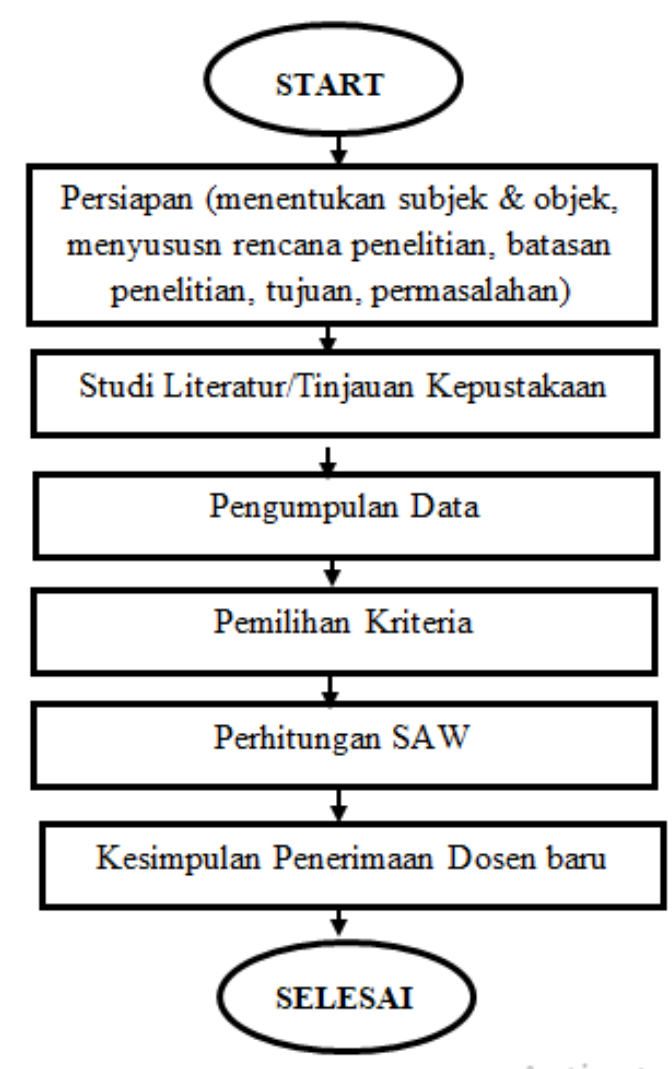

Gambar 1 Tahapan Penelitian
Penjelasan dari tahapan penelitian gambar 1 adalah:

1. Persiapan (menentukkan subjek dan objek, menyusun rencana penelitian, batasan penelitian, tujuan, serta permasalahan)

Pada tahapan ini melakukan persipan untuk menentukkan judul penerimaan dosen baru di Universitas IGM dan permasalahan yang membuat lama dalam menganalisa penerimaan dosen baru di UniversitasIGM

2. Studi literature/ Tinjauan kepustakaan Menjelaskan teori-teori apa yang menunjang penelitian tersebut seperti metode SAW, penerimaan dosen baru, SPK

3. Pengumpulan Data

Pada tahapan ini data di kumpulkan dari beberapa jurnal pendukung serta data wawancara penerimaan dosen baru di bagian biro administrasi umum maupun data arsip yang tersimpan.

4. Pemilihan Kriteria

Untuk pemilihan kriteria kita sesuaikan dengan kriteria dari Universitas IGM baik dari wawancara maupun data arsip yang tersimpan serta jurnal-jurnal yang mendukung penelitian tersebut.

5. Perhitungan SAW

Dalam perhitungan ini berdasarkan penilaian dari 3 kategori penilaian yakni tes kualifikasi pendidikan, tes psikotes dan tes wawancara, kemudian di tentukan bobot mana yang paling tinggi dari kriteria tersebut dengan menggunakan metode SAW dalam pengolahan datanya.

6. Kesimpulan Penerimaan Dosen Baru Kesimpulan ini di dapatkan setelah dilakukan pembobotan dengan metode SAW sehingga di dapatkan 4 penilaian tertinggi agar memudahkan dalam penentuan perangkingan. 


\subsection{Metode Pengumpulan Data}

1. Wawancara Metode wawancara adalah diskusi langsung dengan pihak yang bersangkutan yakni Kepala Biro Administrasi umum untuk mengetahui kriteria penelitian dan dosen yang di terima sebelumnya.

2. Observasi Metode merupakan suatu metode pengambilan data dengan cara mengamati langsung tempat dan objek yang akan diteliti. Dalam penelitian ini yang menjadi objek penelitian yaitu Dosen Universitas IGM.

3. Studi Literatur Studi ini dimaksudkan untuk mengumpalkan dan memperoleh data yang tepat untuk penelitian dengan cara mempelajari, membaca, dan mencatat literatur dari beberapa buku maupun jurnal yang berkaitan dengan permasalahan di atas.

\subsection{Penentuan Kriteria}

Dalam UU No 14 Tahun 2005 disebutkan bahwa untuk menjadi seorang dosen minimal haru memenuhi beberapa persyaratan umum diantaranya prinsip profesionalisme; kualifikasi akademik dosen; memiliki prestasi luar biasa; sehat jasmani rohani; kemampuan bahasa inggris; memiliki kompetensi; berkelakuan baik. Untuk PTS dan PTN bisa menambahkan kriteria dalam penerima dosen baru sesuai yang di butuhkan dari pihak PTS dan PTN tersebut. [15]

Untuk kriteria dalam penerimaan dosen baru di Universitas IGM didapatkan dari wawancara langsung dengan biro administrasi umum, data arsip Universitas IGM serta jurnal ([5], [6]. [16]) sebagai berikut:
1. Kualifikasi Pendidikan

a. Syarat pendidikan minimal yang di tempuh menjadi dosen tetap adalah S2. Kualifikasi pendidikan dilihat ijazah dan transkip nilai terakhir S2 ataupun S3 dari perguruan tinggi dalam negeri ataupun perguruan tinggi luar negeri serta lineritas dengan program studi yang ada pada Universitas IGM yaitu Teknik Informatika, Sistem Informasi, Sistem komputer, Manajemen Informatika, manajemen, akuntansi, magister manajemen, teknik sipil, arsitektur, survei dan pemetaan. Perencanaan wilayah dan kota, pemerintahan, desain komunikasi visual serta pendidikan bahasa inggris.

b. Sertifikat profesi (tambahan) misalnya : sertifikat kompetensi

2. Tes Psikotes

Tes psikotes yang diadakan di Universitas IGM bekerja sama dengan pihak ketiga. Kriteria ini terdiri dari Kemampuan, sikap kerja dan Kepribadian. Kriteria kemampuan umum terdiri dari inteligensi, daya tangkap, daya analisis, sub kriteria sikap kerja terdiri dari ketelitian kerja, ketekunan, sistematika kerja, serta sub keriteria kepribadian terdiri dari keterampilan interpersonal, kepercayaan diri, motivasi dan pengambilan keputusan. Penilaian tes psikotes ini sangat berpengaruh untuk mengikuti ke tahap berikutnya.

3. Tes Wawancara

Pada Tes wawancara di lakukan melalui 3 tahapan yakni tes wawancara dengan Dekan, tes wawancara Warek 1 dan Warek 2, dan tes wawancara dengan Biro Administrasi Akademik (BAA) atau Biro Administrasi Umum (BAU). 


\subsection{Metode SAW}

Dalam mengelola perhitungan dengan metode SAW terdiri dari beberapa tahapan yang bertujuan untuk memudahkan dalam penentuan penerimaan dosen baru di Universitas IGM. Di bawah ini ada beberapa tahapan SAW :

a. Menentukan kriteria-kriteria yang akan dijadikan acuan dalam pengambilan keputusan yaitu $\mathrm{C} 1$ sampai dengan $\mathrm{C} 4$ yakni Kualifikasi Pendidikan, tes psikotes, tes kesehatan dan tes wawancara.

b. Menentukan rating kecocokan setiap alternatif

Untuk penentuan ini berdasarkan pemberian penilaian terhadap calon dosen baru tersebut, nilai ini di dapat dari penilaian dari keempat kriteria tersebut. Setelah itu menentukan bobot dari hasil penilaian tersebut.

c. Membuat matrik keputusan berdasarkan kriteria (Ci), kemudian melakukan normalisasi matrik berdasarkan persamaan yang disesuaikan dengan jenis attribut (Atribut keuntungan atau atribut biaya) sehingga diperoleh matrik ternormalisasi.

Matrik keputusan bertujuan untuk mengelolah penilaian berdasarkan kriteria penerimaan dosen baru, selanjutkan di normalisasikan untuk menghasilkan tabel matrik sehingga memudahkan dalam pengelolaan penilaian.

d. Melakukan proses perangkingan, yaitu mengalikan matrik ternormalisasi dengan vektor bobot

Perangkingan di dapat setelah melakukan beberapa tahapan diatas untuk melihat nilai tertinggi sampai nilai terendah yang di dapat dari hasil penilaian.

\section{HASIL DAN PEMBAHASAN}

\subsection{Hasil Penelitian}

Dalam penelitian ini menggunakan metode SAW untuk mengelola hasil penelitian penerimaan dosen baru di Universitas IGM.

1. Penentuan Kriteria (Ci)

Kriteria penentuan penilaian diambil adalah kualifikasi pendidikan, nilai tes psikotes serta nilai wawancara [17], [18].

a. Kriteria Kualifikasi Pendidikan

kualifikasi pendidikan pada dosen salah satu syarat mutlak yang harus ada dan di penuhi. Pendidikan Dosen saat ini minimal kualifikasinya jenjang S2 (Magister) serta S3 baik tamatan dalam negeri maupun luar negeri yang sesuai dengan bidang keahliannya. Selain itu juga, calon dosen mempunyai nilai tambah apabila calon dosen tersebut telah memiliki Sertifikat kompetensi. Sertifikat kompeternsi adalah bidang keahlian dan keterampilan yang khusus yang dimiliki calon dosen. Sehingga kriteria untuk kualifikasi pendidikan yakni Ijasah S2 atau S3 sesuai dengan bidang keahliaannya dan sertifikasi kompetensi. Di Universitas IGM untuk Kualifikasi pendidikan akan di cek dan di validasi oleh Rektor, Wakil Rektor 1, dan Wakil Rektor 2 serta Dekan yang bersangkutan.

Tabel 1 Kriteria Nilai Kualifikasi Pendidikan

\begin{tabular}{|c|}
\hline Kriteria \\
\hline $\begin{array}{c}\text { Ijazah S2 atau S3 sesuai dengan bidang } \\
\text { keahlian }\end{array}$ \\
\hline Sertifikat Kompetensi \\
\hline
\end{tabular}

Sumber: [5], [6]. [16], data arsip Universitas IGM.

\section{b. Kriteria Tes Psikotes}

Sebuah Tes psikotes merupakan tes penggambaran diri. Tes psikotes terdapat beberapa kriteria yaitu kemampuan umum, sikap kerja dan kepribadian. Tes ini melihat sifat pribadi, bakat, keahlian serta sikap yang di miliki calon dosen. Biasanya dapat 
terbaca dari jawaban, dapat di lihat gambaran diri calon dosen tersebut. Di Universitas IGM tes psikotes di laksanakan dengan bekerjasama dengan pihak ketiga yang telah melakukan kerjasama di mulai dengan penyediaan tempat, soal dan pengelolaan jawaban (hasil) yang akan di terima calon dosen

Tabel 2 Kriteria Nilai Nilai Tes Psikotes

\begin{tabular}{|c|}
\hline Kriteria \\
\hline Kemampuan Umum \\
\hline Sikap Kerja \\
\hline Kepribadian \\
\hline
\end{tabular}

Sumber Sumber: [5], [6]. [16], data arsip Universitas IGM

\section{c. Kriteria Tes Wawancara}

Tes ini menunjukkan secara langsung keammapuan, keahlian serta kecakapan dari calon dosen, di karenakan calon dosen menjawab langsung semua pertanyaan yang di sampaikan selama tes berlangsung. Di universitas IGM tes wawancara ini ada 3 tahap pertama yakni wawancara dengan dekan dan kaprodi. Tahap ini Dekan dan kaprodi memberikan pertanyaan seputar bidang keahlian dosen, materi kuliah yang akan calon dosen kuasai dan kemampuan calon dosen menjawab pertanyaan tentang ilmu pengetahuan. Tahap kedua yakni wawancara dengan Wakil Rektor 1 dan Wakil Rektor 2, yang membahas tentang pertanyaan rencana ke depan calon dosen, tujuan calon dosen serta kurikulum yang akan di bebankan kepada calon dosen. Tahap ketiga yakni dengan BAA atau BAU menjelaskan tentang seputar peraturan, tata tertib, dan punishment serta gaji atau kompensai yang akan di terima selama menjadi Dosen.
Tabel 3 Kriteria Nilai Wawancara

\begin{tabular}{|c|}
\hline Kriteria \\
\hline Kemampuan Penguasaan Materi Kuliah \\
\hline Kemampuan Menjawab Pertanyaan \\
\hline Memiliki Wawasan kedepan \\
\hline
\end{tabular}

Sumber Sumber: [5], [6]. [16], data arsip Universitas IGM

Tabel 4 Katagori Penilaian

\begin{tabular}{|c|c|c|c|}
\hline Uji Tes & Kategori & Kriteria & Bobot \\
\hline \multirow{5}{*}{$\begin{array}{l}\text { Kualifikasi } \\
\text { Pendidikan }\end{array}$} & \multirow{3}{*}{$\begin{array}{l}\text { Ijazah S2 } \\
\text { atau S3 } \\
\text { sesuai } \\
\text { dengan } \\
\text { bidang } \\
\text { keahlian } \\
\text { (C1) }\end{array}$} & sesuai & 10 \\
\hline & & & \\
\hline & & $\begin{array}{l}\text { Tidak } \\
\text { sesuai }\end{array}$ & 0 \\
\hline & \multirow{2}{*}{$\begin{array}{l}\text { Sertifikat } \\
\text { kompeten } \\
\text { si (C2) }\end{array}$} & ada & 5 \\
\hline & & $\begin{array}{l}\text { Tidak } \\
\text { ada }\end{array}$ & 0 \\
\hline \multirow{6}{*}{ Tes Psikotes } & \multirow{3}{*}{$\begin{array}{l}\text { Kemampu } \\
\text { an Umum } \\
\text { (C3) }\end{array}$} & Baik & 10 \\
\hline & & Cukup & 5 \\
\hline & & $\begin{array}{l}\text { Tidak } \\
\text { cukup }\end{array}$ & 0 \\
\hline & \multirow[t]{3}{*}{$\begin{array}{l}\text { Sikap } \\
\text { Kerja (C4) }\end{array}$} & $\begin{array}{l}\text { Pekerja } \\
\text { Keras }\end{array}$ & 10 \\
\hline & & $\begin{array}{l}\text { Sistemat } \\
\text { ika } \\
\text { Kerja }\end{array}$ & 10 \\
\hline & & $\begin{array}{l}\text { Tidak } \\
\text { mampu } \\
\text { bekerja } \\
\text { keras } \\
\text { dan } \\
\text { tidak } \\
\text { Sistemat } \\
\text { ika kerja }\end{array}$ & 0 \\
\hline \multirow{7}{*}{ Wawancara } & \multirow{3}{*}{$\begin{array}{l}\text { Penguasaa } \\
\text { n Materi } \\
\text { Kuliah } \\
\text { (C5) }\end{array}$} & Baik & 10 \\
\hline & & Cukup & 5 \\
\hline & & $\begin{array}{l}\text { Tidak } \\
\text { Cukup }\end{array}$ & 0 \\
\hline & \multirow{3}{*}{$\begin{array}{l}\text { Kemampu } \\
\text { an } \\
\text { Menjawab } \\
\text { Pertanyaan } \\
\text { (C6) }\end{array}$} & Baik & 10 \\
\hline & & Cukup & 5 \\
\hline & & $\begin{array}{l}\text { Tidak } \\
\text { Cukup }\end{array}$ & 0 \\
\hline & Memiliki & Baik & 10 \\
\hline
\end{tabular}




\begin{tabular}{|c|c|c|}
\hline Wawasan & Cukup & 5 \\
\hline $\begin{array}{l}\text { Kedepan } \\
\text { (C7) }\end{array}$ & $\begin{array}{l}\text { Tidak } \\
\text { Cukup }\end{array}$ & 0 \\
\hline
\end{tabular}

Sumber : [5], [6]. [16], data arsip Universitas IGM

Setiap nilai yang dicantumkan pada setiap alternatif di setiap kriteria adalah nilai kecocokan (nilai terbesar adalah terbaik), maka semua kriteria yang diberikan diasumsikan kriteria keuntungan sebagai berikut :

1. Rating Kecocokan dari Setiap alternatif pada setiap kriteria

Tabel 5 Ranting Kecocokan Kategori

\begin{tabular}{|l|l|l|l|l|l|l|l|}
\hline Alternatif & \multicolumn{7}{|c|}{ Kategori } \\
\cline { 2 - 8 } Pelamar & C1 & C2 & C3 & C4 & C5 & C6 & C7 \\
\hline P1 & 10 & 5 & 10 & 10 & 5 & 10 & 10 \\
\hline P2 & 10 & 0 & 10 & 10 & 5 & 5 & 10 \\
\hline P3 & 10 & 0 & 0 & 10 & 5 & 5 & 5 \\
\hline P4 & 10 & 5 & 10 & 10 & 10 & 5 & 10 \\
\hline
\end{tabular}

Sumber : data olahan dengan metode SAW

\section{Penentuan Bobot}

Prioritas yang tertinggi pada penerimaan dosen baru di beri dengan bobot 10 sedangkan prioritas penunjang di beri bobot 5 .

$\mathrm{C} 1=10, \mathrm{C} 2=5, \mathrm{C} 3=10, \mathrm{C} 4=10, \mathrm{C} 5=10$, $\mathrm{C} 6=10, \mathrm{C} 7=5$.

$$
\mathrm{W}=(10,5,10,10,10,10,5)
$$

3. Bentuk Matrik Keputusan Berdasarkan Tabel kecocokan

$X=\left[\begin{array}{rrrrrrr}10 & 5 & 10 & 10 & 5 & 10 & 10 \\ 10 & 0 & 10 & 10 & 5 & 5 & 10 \\ 10 & 0 & 0 & 10 & 5 & 5 & 5 \\ 10 & 5 & 10 & 10 & 10 & 5 & 10\end{array}\right]$

1. Normalisasi matriks $X$

$$
\begin{aligned}
& \mathrm{R}_{11}=\frac{10}{\max \{10,10,10,10\}}=\frac{10}{10}=1 \\
& \mathrm{R}_{21}=\frac{5}{\max \{10,10,10,10\}}=\frac{5}{10}=0,5 \\
& \mathrm{R}_{31}=\frac{10}{\max \{10,10,10,10\}}=\frac{10}{10}=1 \\
& \mathrm{R}_{41}=\frac{10}{\max \{10,10,10,10\}}=\frac{10}{10}=1 \\
& \mathrm{R}_{51}=\frac{5}{\max \{10,10,10,10\}}=\frac{5}{10}=0,5
\end{aligned}
$$

$$
\begin{aligned}
& \mathrm{R}_{61}=\frac{10}{\max \{10,10,10,10\}}=\frac{10}{10}=1 \\
& \mathrm{R}_{71}=\frac{10}{\max \{10,10,10,10\}}=\frac{10}{10}=1
\end{aligned}
$$

Menghasilkan tabel matrik sebagai berikut :

Tabel 6 Normalisasi Matrik

\begin{tabular}{|l|l|l|l|l|l|l|l|}
\hline \multirow{2}{*}{$\begin{array}{l}\text { Alternatif } \\
\text { Pelamar }\end{array}$} & \multicolumn{7}{|c|}{ Kategori } \\
\cline { 2 - 9 } & C1 & C2 & C3 & C4 & C5 & C6 & C7 \\
\hline P1 & 1 & 0,5 & 1 & 1 & 0,5 & 1 & 1 \\
\hline P2 & 1 & 0 & 1 & 1 & 0,5 & 0,5 & 1 \\
\hline P3 & 1 & 0 & 0 & 1 & 0,5 & 0,5 & 0,5 \\
\hline P4 & 1 & 0,5 & 1 & 1 & 1 & 0,5 & 1 \\
\hline
\end{tabular}

Sumber : data olahan dengan metode SAW

Selanjutnya di transformasikan ke dalam

\begin{tabular}{|c|c|c|c|c|c|c|c|c|}
\hline \multirow{2}{*}{$\begin{array}{l}\text { Altern } \\
\text { atif } \\
\text { Pelam } \\
\text { ar }\end{array}$} & \multicolumn{7}{|c|}{ Kategori } & \multirow[b]{2}{*}{ Hasil } \\
\hline & $\mathrm{C} 1$ & $\mathrm{C} 2$ & $\begin{array}{l}\mathrm{C} \\
3\end{array}$ & $\begin{array}{l}\text { C } \\
4\end{array}$ & $\begin{array}{l}\mathrm{C} \\
5\end{array}$ & $\begin{array}{l}\mathrm{C} \\
6\end{array}$ & $\mathrm{C} 7$ & \\
\hline $\mathrm{P} 1$ & 10 & 2,5 & 5 & 10 & 5 & 10 & 10 & 52,5 \\
\hline $\mathrm{P} 2$ & 10 & 0 & $\begin{array}{l}1 \\
0\end{array}$ & 10 & 5 & 5 & 10 & 50 \\
\hline P3 & 10 & 0 & 0 & 10 & 5 & 5 & 2,5 & 32,5 \\
\hline $\mathrm{P} 4$ & 10 & 2,5 & $\begin{array}{l}1 \\
0\end{array}$ & 10 & 10 & 5 & 10 & 57,5 \\
\hline
\end{tabular}
matrik sebagai berikut :

$$
X=\left[\begin{array}{ccccccc}
1 & 0,5 & 1 & 1 & 0,5 & 1 & 1 \\
1 & 0 & 1 & 1 & 0,5 & 0,5 & 1 \\
1 & 0 & 0 & 1 & 0,5 & 0,5 & 0,5 \\
1 & 0,5 & 1 & 1 & 1 & 0,5 & 1
\end{array}\right]
$$

4. Proses Perangkingan

Perengkingan diproleh berdasarkan persamaan matriks normalisasi (Ri) dengan Bobot Preferensi (W) sebagai berikut :

Tabel 7 Perangkingan

Sumber : data olahan dengan metode SAW

\subsection{Pembahasan}

Kriteria dalam penentuan dosen baru terdiri dari 3 tes yang akan di uji kepada calon dosen yakni kualifikasi pendidikan, tes psikotes, dan tes wawancara.

Disetiap tes yang akan di uji terdiri beberapa kriteria untuk kualifikasi pendidikan melihat kesesuaian antara ijazah dengan bidang keahlian, ditambah lagi apabila calon dosen memiliki sertifikat 
kompetensi, calon dosen akan mempunyai nilai tambah dalam penilaian.

Untuk Tes Psikotes di lihat hasilnya berdasarkan kemamapuan umum, ini melihat calon dosen tentang kemampuan umum sampai mana yang di milikinya, sedangkan untuk sikap kerjanya ini akan menentukan calon dosen dalam bekerja sikapnya pekerja keras ataukah tidak mampu bekerja keras dan di bawah tekanan.

Untuk Tes Wawancara, di lakukan 3 tahap yakni pada dekan dan kaprodi, wakil rektor 1 dan wakil rektor 2 dan BAU atau BAA. Calon dosen harus dapat menjelaskan materi di depan Dekan dan kaprodi tentang materi yang di ampuh, seberapa paham dan mengerti calon dosen tentang materi tersebut. Untuk kemampuan menjawab pertanyaan itu dilihat saat melakukan tes dengan wakil rektor 1 dan rektor 2 . Pertanyaan seputar kecakapan calon dosen dalam berinteraksi dan melihat karakter calon dosen secara langsung. Kemudian untuk tes wawasan kedepan akan di lakukan BAU atau BAA rencana dan target apa yang akan dilakukan calon dosen dalam kedepan ini merupan nilai tambah apabila mempunya wawasan kedepan yang telah terorganisir dan sistematik.

Hasil dari pengelolaan perangkingan dalam pengelolaan penilaian normalisasi dengan bobot dengan menggunakan metode SAW maka penilaian untuk penentuan penerimaan dosen baru yakni pelamar $1=$ 52,5; pelamar $2=50$, pelamar $3=32,5$ dan pelamar $4=57,5$. Maka dapat di lihat bahwa pelamar 4 memiliki nilai tertinggi yakni 57,5 menyatakan bahwa pelamar 4 di rekomendasikan menjadi dosen baru di Universitas IGM. Pelamar 4 memiliki kelebihan sertifikat kompetensi dan nilai penunjang lainnya dengan bobot 10 hanya di kriteria C6 pelamar 4 memiliki nilai bobot 5 yang menyatakan bahwa pelamar 4 hanya mampu menjawab pertanyaan dikarenakan gugup terhadap wakil rektor 1 dan wakil rektor 2. Dan Untuk pelamar terendah pada pelamar 3 yang memiliki penilaian 32,5.

\section{KESIMPULAN}

Berdasarkan hasil dari penentuan penerimaan dosen baru dengan menggunakan SAW (Simple Additive Weighting), maka dapat disimpulkan sebagai berikut :

1. Penilaian di tentukan berdasarkan 3 katagori dengan 7 kriteria. Untuk 3 kategori yakni kualifikasi pendidikan, tes psikotes dan tes wawancara sedangkan 7 kriteria yakni ijazah S2 atau S3 yang sesuai dengan bidang keahlian, sertifikasi kompetensi, kemmapuan umum, sikap kerja, Penguasaan materi ku

2. Penilaian terbesar berdasarkan perangkingan penilaian menggunakan Metode SAW.

3. Hasil dari peniliaan penentuan penerimaan dosen baru dilihat dari perangkingan tertinggi dengan nilai rangking terbesar dengan pengelolaan metode SAW.

\section{SARAN}

Saran yang di berikan kepada Universitas IGM yaitu penentuan penerimaan dosen baru yang akan datang dapat menggunakan perhitungan metode SAW ini apabila pelamar dosen baru banyak.

\section{DAFTAR PUSTAKA}

[1] S. N. H. Yasir, "Manajemen Peningkatan Kualitas Dosen (Studi Kasus Pada Fakultas Tarbiyah Uin Malang)," J. Res. Thought Islam. Educ., Vol. 1, No. 1, Pp. 96-107, 2018.

[2] Agustina Heryati, "Pengaruh Kompensasi Dan Disiplin Kerja 
Terhadap Kinerja Dosen Di Sekolah Tinggi Ekonomi Dan Bisnis Syariah (Stebis) Indo Global Mandiri," Econ. Sharia, Vol. 2, Pp. 35-60, 2017.

[3] K. Ftik, "Analisa Penerimaan Dosen Baru Dengan Menggunakan Saw ( Simple Additive Weighting ) Nurtriana Hidayati Fakultas Teknologi Informasi Dan Komunikasi Universitas Semarang Abstract - Penerimaan Dosen Baru Merupakan Salah Satu Proses Pengambilan Keputusan Berda," Vol. 14, Pp. 12-17, 2016.

[4] A. Heryati And M. I. Herdiansyah, "The Application Of Data Mining By Using K-Means Clustering Method In Determining New Students' Admission Promotion Strategy," Int. J. Eng. Adv. Technol., Vol. 9, No. 3, Pp. 824-833, 2020.

[5] D. S. Lutfi, "Sistem Pendukung Keputusan Penerimaan Dosen Baru Dengan Metode Simple Additive Weighting (Saw)," J. Teknol. Inf. Dan Terap., Vol. 4, No. 1, Pp. 1116, 2019.

[6] S. S. Sundari And Y. F. Taufik, "Pegawai Baru Dengan Menggunakan Metode Simple Additive Weighting ( Saw )," Sisfotenika, Vol. Vol. 4, No, Pp. 140-151, 2014.

[7] H. Asnal And F. Zoromi, "Penerapan Metode Multi Atribut Utility Theory Dalam Sistem Seleksi Penerimaan Dosen Di Stmik-AmikRiau.," Rabit J. Teknol. Dan Sist. Inf. Univrab, Vol. 5, No. 1, Pp. 4453, 2020.

[8] F. Frieyadie, "Penerapan Metode Simple Additive Weight (Saw) Dalam Sistem Pendukung Keputusan Promosi Kenaikan Jabatan," J. Pilar Nusa Mandiri,
Vol. 12, No. 1, Pp. 37-45, 2016.

[9] A. Arifin, J. D. Raharjo, And A. Darmadi, "Sistem Penunjang Keputusan Penerimaan Dosen Dengan Metode Analytic Hierarchy Process," J. Sisfotek Glob., Vol. 5, No. 1, 2015.

[10] E. Yullyanti, "Analisis Proses Rekrutmen Dan Seleksi Pada Kinerja Pegawai Di Sekretariat Jenderal Desdm Dengan Metode Sem," J. Ilmu Admninistrasi Dan Organ., Vol. 16, No. 3, Pp. 131139, 2016.

[11] H. Nurcahyo, A. Suryoputro, And S. Jati, "Analisis Proses Rekrutmen Dan Seleksi Tenaga Kesehatan Tim Nusantara Sehat Dalam Program Nusantara Sehat Kementerian Kesehatan Republik Indonesia," $J$. Kesehat. Masy., Vol. 4, No. 4, Pp. 60-69, 2016.

[12] T. Noviyanti, "Sistem Penunjang Keputusan Dalam Penerimaan Beasiswa Ppa Menggunakan Metode Analytic Hierarchy Process (Ahp) (Studi Kasus: Universitas Gunadarma)," J. Ilm. Teknol. Dan Rekayasa, Vol. 24, No. 1, Pp. 3545, 2019.

[13] Saefudin And S. Wahyuningsih, "Sistem Pendukung Keputusan Untuk Penilaian Kinerja Pegawai Menggunakan Metode Analytical Hierarchy Process (Ahp) Pada Rsud Serang," J. Sist. Inf., Vol. 1, No. 1, P. 33, 2014.

[14] M. F. Asnawi And M. A. M. Baihaqy, "Implementasi Metode Simple Additive Weigth (Saw) Pada Sistem Pendukung Keputusan Penentuan Dosen Berprestasi," J. Penelit. Dan Pengabdi. Kpd. Masy. Unsiq, Vol. 6, No. 3, Pp. 198-205, 2019.

[15] Undang-Undang, Undang-Undang 
Republik Indonesia Nomor 14

Tahun 2005. 2005.

[16] K. Ftik, "Analisa Penerimaan Dosen Baru Dengan Menggunakan Saw ( Simple Additive Weighting ) Nurtriana Hidayati Fakultas

Teknologi Informasi Dan

Komunikasi Universitas Semarang Abstract - Penerimaan Dosen Baru Merupakan Salah Satu Proses Pengambilan Keputusan Berda," Vol. 14, Pp. 12-17, 2016.

[17] A. Sunyoto, P. Studi, T. Informatika, And S. C. Dosen, "Sistem Pendukung Keputusan Seleksi Penerimaan Dosen Di Stmik Amikom Yogyakarta Menggunakan Metode Topsis Dan Borda," Vol. 10, No. 2, Pp. 44-61, 2017.

[18] N. Hidayati, T. Waluyo, And E. I. H. Ujianto, "Sistem Pendukung Pengambilan Keputusan Penerimaan Dosen Dengan Metode Ahp ( Studi Kasus Universitas Teknologi Yogyakarta )," Vol. 7, No. 2, Pp. 63-69, 2019. 